\title{
Social Support and Clinical Outcomes During Antiviral Therapy for Chronic Hepatitis C
}

\author{
Donna M. Evon, $\mathrm{PhD}^{1}$, Denise A. Esserman, $\mathrm{PhD}^{2,3}$, Darmendra Ramcharran, $\mathrm{PhD}^{4, *}$, Jason \\ E. Bonner, $\mathbf{P h D}^{1}$, and Michael W. Fried, $\mathbf{M D}^{1}$ for the Virahep-C Study Group \\ ${ }^{1}$ Division of Gastroenterology and Hepatology, University of North Carolina, Chapel Hill, NC \\ ${ }^{2}$ Department of Medicine, University of North Carolina, Chapel Hill \\ ${ }^{3}$ Department of Biostatistics, Gillings School of Public Health, University of North Carolina, \\ Chapel Hill \\ ${ }^{4}$ Independent consultant, Providence, RI
}

\begin{abstract}
Objective-To determine if social support (SS) is associated with clinical outcomes during antiviral therapy for chronic hepatitis $\mathrm{C}$ virus (HCV).

Methods-Data from 394 patients who participated in the prospective, longitudinal VIRAHEP-C study were examined. VIRAHEP-C enrolled 401 adults with HCV to evaluate factors associated with antiviral treatment response. Perceived SS was measured using the Medical Outcome Study Social Support Survey (MOS-SSS) at baseline and treatment week 24. Scores were calculated as a continuous variable ranging from $0 \%-100 \%$ with higher scores indicating greater support. Two SS variables were created: (1) baseline SS (BL-SS) and (2) change in SS from baseline to treatment week 24 (CH-SS). The primary endpoint was sustained virological response (SVR) six months post-treatment. Intermediate outcomes included: symptom-reporting; virological response at treatment week 24; medication adherence; neuropsychiatric adverse events; and dose reductions and premature medication discontinuation. The relative risk of each outcome was estimated using modified Poisson regression models or linear mixed models.
\end{abstract}

Results-BL-SS was relatively high (mean $=79 \%$ ). Overall, SS declined from baseline to treatment week 24 (median change: $-1.3 \% ; p<0.01$ ). Neither BL-SS nor $\mathrm{CH}-\mathrm{SS}$ were associated with SVR. However, BL-SS was associated with multiple symptoms (fatigue, headache, irritability, aches/pains) during treatment, even after adjusting for baseline depression, which was significantly associated with symptom-reporting.

Conclusions-SS was not directly associated with efficacy measures, such as SVR. However, baseline SS predicted an increase in symptomatology over the course of antiviral therapy. Baseline depression was also significantly associated with symptom-reporting.

() 2011 Elsevier Inc. All rights reserved.

Corresponding Author: Donna M. Evon, Ph.D., Division of Gastroenterology and Hepatology, CB\# 7584, 8010 Burnett-Womack, University of North Carolina, Chapel Hill, NC 27599, Telephone: (919) 966-6732, donna_evon@med.unc.edu, Fax: (919) 966-1700. *Current affiliation: Pfizer Inc, New London, CT

Publisher's Disclaimer: This is a PDF file of an unedited manuscript that has been accepted for publication. As a service to our customers we are providing this early version of the manuscript. The manuscript will undergo copyediting, typesetting, and review of the resulting proof before it is published in its final citable form. Please note that during the production process errors may be discovered which could affect the content, and all legal disclaimers that apply to the journal pertain.

Disclaimer: The content is solely the responsibility of the authors and does not necessarily represent the official views of the National Center for Research Resources or the National Institutes of Health. 


\section{Keywords}

Social Support; Interferon; Treatment; Efficacy; Depression; Virological Response

\section{Introduction}

Chronic hepatitis $\mathrm{C}$ virus (HCV) is the most common blood-borne infection, five times more prevalent than HIV/AIDS, and affects 180 million people worldwide $(1,2)$. HCV can lead to cirrhosis and liver cancer, resulting in 10,000 deaths per year in the United States alone, and is the leading indication for liver transplantation $(1,3,4)$. The individual and public health burden of $\mathrm{HCV}$ is significant, and expected to increase in the next 20 years $(4,5)$.

Fortunately, curative treatment for HCV exists. The current treatment consists of subcutaneous injections of pegylated interferon on a weekly basis, and taking oral ribavirin twice daily (PEG/RBV) for up to 48 weeks(6). If patients have undetectable virus six months post-treatment (known as a sustained virological response (SVR)), this "virological cure" is associated with reduced risk for liver complications and improvements in quality of life $(1,7-10)$.

Unfortunately many patients poorly tolerate the treatment regimen. This may be due to both pre-existing biopsychosocial issues, as well as difficulty tolerating the side effects of PEG/ RBV treatment. Many individuals with HCV have co-existing medical conditions, reduced quality of life, comorbid depression, anxiety, irritability, and perceive social stigmatization due to $\mathrm{HCV}(11,12)$. Moreover, PEG/RBV can cause numerous hematologic, physical, and neuropsychiatric side effects, or can exacerbate pre-existing conditions, particularly neuropsychiatric symptoms $(7,13-15)$.

In a previous investigation of depressive symptoms during antiviral therapy, Evon et al. discovered that lower social support (SS) at baseline was associated with several markers of depression at baseline. SS was also the strongest predictor of incident depression during treatment. This relationship was interesting and indicated that perhaps, the relationship between SS and other treatment outcomes warranted further investigation. The prevalence of psychiatric and addiction disorders among HCV patients is high, and perceived social stigma is common $(12,16)$. These factors can erode SS and theoretically undermine a successful course of treatment $(11,17-19)$. Moreover, HIV literature suggests that SS may be important to antiretroviral treatment outcomes, such that higher SS is associated with greater likelihood of viral suppression (20). Based on this evidence, we hypothesized that SS could impact the primary endpoint of PEG/RBV treatment, namely SVR, or could negatively impact intermediate clinical outcomes such as medication-taking adherence or the ability to tolerate side effects, which in turn, could impact SVR. To our knowledge, no study has examined the effects of SS on clinical outcomes during antiviral treatment for HCV, although it is widely assumed that adequate SS is an important component of treatment success $(11,19,21-24)$.

The large, prospective, longitudinal U.S. National Institutes of Health (NIH) funded study, Viral Resistance to Antiviral Therapy of Chronic Hepatitis C (VIRAHEP-C), offers a unique opportunity to investigate the impact of SS on clinical outcomes during antiviral treatment for $\mathrm{HCV}$, a treatment commonly associated with numerous adverse side effects and requires a high rate of medication adherence $(16,17)$. While many indirect and mediating pathways may exist, this initial investigation was designed to evaluate the direct relationship between SS and primary and intermediate clinical outcomes. Given the association between SS and depression in our previous study (25), we were also interested in assessing whether 
depression was significantly associated with any significant SS-clinical outcome relationships. Thus, the specific aims of this study are as follows:

1. To evaluate whether baseline SS or the change in SS are associated with SVR, the primary efficacy measure for antiviral therapy;

2. To determine if baseline SS or the change in SS are associated with the following intermediate clinical outcomes which could impact SVR: symptom-reporting; virological response at treatment week 24; medication-taking adherence; neuropsychiatric adverse events; and dose reductions and premature medication discontinuation secondary to neuropsychiatric adverse events; and

3. To examine the effects of depression on any statistically significant relationships between SS and clinical outcomes.

\section{Methods}

\section{Design}

This study utilized the prospectively collected data from the NIH-funded study VIRAHEP-C (26).VIRAHEP-C enrolled approximately equal numbers of African American $(n=196)$ and Caucasian $(n=205)$ adults with chronic hepatitis C, genotype 1 infection at 8 U.S. medical centers to evaluate factors associated with antiviral treatment response. Participants were treated with PEG/RBV for up to 48 weeks, however those with detectable virus at week 24 were discontinued from therapy. Patients attended a baseline visit and then follow-up visits for data collection at treatment weeks 2, 4, 8, 12 and monthly thereafter. All patients were followed up to 6 months post-treatment to assess SVR. All subjects provided written informed consent and the study was approved by the Institutional Review Boards of all participating sites. Inclusion and exclusion criteria for the VIRAHEP-C parent study are described elsewhere, but included: alcohol consumption of more than two drinks or equivalent (>20 grams) per day; evidence of alcohol or drug abuse within 6 months prior to screening; any current (within past 6 months) severe psychiatric disorder such as depression, schizophrenia, bipolar illness, obsessive-compulsive disorder, severe anxiety, or personality disorder; and a prior suicide attempt, hospitalization for psychiatric disease, or a period of disability or impairment due to a psychiatric disease within the past 5 years. Patients whose psychiatric disease was controlled by medication and deemed psychologically stable by the investigator were eligible for participation (26). With the exception of the primary endpoint (SVR), the current analyses were focused on the baseline to treatment week 24 time period, since a large number of patients were discontinued from treatment at 24 weeks given protocol-defined discontinuation rules for nonresponders. The initial sample was limited to individuals with a baseline measure of SS $(n=394)$.

Measures

Baseline Patient Characteristics-Age and depression were analyzed as continuous variables; sex, race, marital status, educational level, employment status, health insurance, alcohol consumption, smoking status, source of HCV infection, and liver disease (severe fibrosis: Ishak fibrosis score $\geq 3$ ) were analyzed as categorical variables.

Social Support-The Medical Outcome Study Social Support Survey (MOS SSS), a reliable and validated 19-item self-report scale, was used to measure individuals' perceptions of available SS (27). The survey consists of one overall SS index, and four separate SS functional subscales measuring: (1) emotional/informational SS, (2) tangible SS, (3) affectionate SS, and (4) positive social interaction. MOS SSS scores were calculated as a continuous variable and analyzed on a transformed percentage scale (potential range of $0 \%-$

J Psychosom Res. Author manuscript; available in PMC 2012 November 1. 
$100 \%$ ) with higher scores indicative of greater support (27). The MOS SSS also included a single item to measure social integration (i.e., quantity of perceived available support) by asking respondents to indicate the number of close friends or relatives with whom they "feel at ease with and can talk to about what's on your mind." The MOS SSS was administered at baseline and week 24 during VIRAHEPC. Two SS variables were created: (1) baseline SS (BL-SS) and (2) change in SS from baseline to treatment week 24 (CH-SS). The planned analyses employed the overall SS score, but post-hoc exploratory analyses explored the four functional subscales and the single social integration item.

Depressive Symptoms-The Center for Epidemiologic Studies-Depression (CES-D) scale, a 20-item self-report scale, was used to measure depressive symptoms at baseline and weeks 4, 8, 12 and monthly thereafter (28). Items range from 0 (never) to 3 (almost always), and total scores range from 0 to 60 . For these analyses, we evaluated the baseline CES-D total score as a continuous measure.

\section{Primary Outcome}

SVR was measured 24 weeks after the end of therapy, and defined as having an undetectable HCV RNA (HCV RNA < $50 \mathrm{IU} / \mathrm{mL}$ ) in serum by qualitative PCR; otherwise subjects (with detectable or an indeterminate read 6 months after completion of PEG/RBV therapy) were considered "non-SVR".

\section{Intermediate Outcomes}

Symptom-Reporting: Six visual analog scales (VASs) were used to assess: (1) overall symptomatology, (2) fatigue, (3) headaches, (4) muscle/joint aches and pains, (5) irritability, and (6) depression. Symptom VASs were assessed at baseline and treatment weeks 1, 2, 4, 6,8 , and monthly thereafter. Participants marked a computerized line via a touch screen which was converted to a continuous 0-10 scale with higher scores indicative of worse symptoms. The VAS depression variable was analyzed in a prior publication and is not described here (26).

Week 24 Virological Response: Subjects with an undetectable serum HCV RNA or an indeterminate read at treatment week 24 were defined as "treatment week 24 responders" and continued on treatment for another 24 weeks; subjects with detectable serum HCV RNA at treatment week 24 were considered "treatment week 24 nonresponders" and were discontinued from treatment.

Medication-taking Adherence (defined by the following two variables) was assessed with a modified version of the Aids Clinical Trial Group Adherence Questionnaire at treatment weeks 4,12 , and 24 for this analysis(29):

- Ribavirin Adherence: Subjects self-reported whether they had missed taking doses of ribavirin for each of the 4 days preceding a clinic visit. If a subject reported taking all 8 doses during those 4 days (i.e., 4 days multiplied by 2 doses per day) for each of weeks 4,12 and 24, they were considered fully adherent. If they missed any dose, they were considered nonadherent.

- Peginterferon Adherence: Subjects reported whether they had missed taking any $\mathrm{PEG} / \mathrm{RBV}$ injections during the 4 weeks preceding a clinic visit. If a subject reported taking all 4 weekly injections for each of weeks 4,12 and 24, they were considered fully adherent. If they missed any injections, they were considered nonadherent.

Neuropsychiatric Adverse Events and Subsequent Dose Reductions (defined by the following two variables) were assessed up to week 24 of the study: 
- Neuropsychiatric Adverse Events: any adverse event that was reported up to treatment week 24, with the event specified as depression, other neuropsychiatric, behavioral event/non-medical, or mental.

- Dose Reductions due to Neuropsychiatric Adverse Events: Defined as a reduction, interruption, or discontinuation of either PEG or RBV due to a neuropsychiatric adverse event (i.e., depression, other neuropsychiatric, behavioral event/nonmedical, or mental).

Premature Study Medication Discontinuations were assessed up to week 24 of the study. They were defined as discontinuation of study medications up to treatment week 24 due to patient intolerance, preference, nonadherence, or study participation discontinuation (defined as discontinuation in the Virahep-C study due to patient withdrawal, loss to followup, or refusal at any time).

\section{Statistical analysis}

Box and whisker plots were used to describe the distribution of BL-SS for the overall scales. The median and interquartile range (IQR) of BL-SS and CH-SS across categorical patient characteristic measures were calculated and differences assessed using a Wilcoxon rank sum (two categories) or Kruskal-Wallis (more than two groups) test. Correlations between the SS variables and continuous patient characteristic variables were assessed with Spearman's correlations. A Wilcoxon sign rank test was used to evaluate whether changes in SS from baseline to treatment week 24 were significantly different than zero. Cohen's $d$ was used to measure the effect sizes and assess their strength (30). Likelihood ratio tests were used to evaluate change in VASs from baseline to treatment week 24.

A Poisson regression model with a robust variance estimator (31) was used to estimate the relative risk (RR) of dichotomous clinical outcome measures (SVR; ribavirin medication adherence; PegIFN medication adherence; neuropsychiatric adverse events; dose reductions due to neuropsychiatric adverse events; premature study medication discontinuation; week 24 virologic response) and the two SS variables (BL-SS; CH-SS). The values of SS were centered about their mean before inclusion in the model and a unit change of RR was equivalent to a $10 \%$ change in the SS scale. To examine symptom VASs over time, a linear mixed model was fit to each VAS including BL-SS, time, and BL-SS by time interaction effects and a random subject effect with an unstructured covariance matrix. No formal methods were used to correct for multiple testing, but to be conservative we set the level of significance to $\alpha=0.01$ for all analyses to reduce the chance of making a Type I error.

Post-hoc analyses were carried out for each of the four functional subscales using the same methods: modified Poisson regression, regressing a BL-SS or CH-SS subscale onto each of the clinical outcomes. For the primary analyses, we utilized the overall SS score because the subscales were, for the most part, highly correlated with one another (all $r$ 's $>0.64 ; p$ 's < 0.01 for baseline measures). This suggested high convergence and minimal discrimination among the subscales, and that use of the overall subscale was both justifiable and parsimonious. We analyzed the association between each of these subscale variables and the clinical outcomes to elucidate any trends which may have been overlooked by using the overall SS scale in the primary analyses. Similarly, we explored the relationship between social integration and the outcomes. All analyses were carried out using SAS version 9.2 (Cary, NC). 


\section{Results}

\section{Patient Characteristics and Social Support}

The characteristics of the overall population $(N=401)$ who participated in the VIRAHEP-C parent study are described elsewhere (26). Of the 394 participants who completed the baseline SS measure and comprise the present study's sample, the median age was 48 years (range: 23 to 70 years), $65 \%$ were male, and 52\% were Caucasian.

The distribution of BL-SS is presented in Figure 1. Baseline SS was relatively high in this study population with $73 \%$ of patients having BL-SS scores greater than 70 (the average MOS-SS score from the normative sample)(27). In those with week 24 SS data $(n=257)$, the median change in overall SS from baseline to treatment week 24 was $-1.3 \%$. While this decrement in SS was statistically significant $(p<0.01)$, a Cohen's $d$ effect size indicated only a small clinically significant effect size $(d=-0.21)$.

The median and IQR of BL-SS and CH-SS across subject characteristics are presented in Table 1. Employment, marital status, health insurance, and smoking status were associated with BL-SS (all p-values <0.01). In general, participants who were married or in a relationship, employed, nonsmokers, or did not have public health insurance, had the highest levels of BL-SS, relative to comparison groups. Baseline CES-D was significantly and negatively correlated with BL-SS $(r=-0.46 ; \mathrm{p}<0.01)$ but not with CH-SS $(r=0.05 ; \mathrm{p}=0.47)$. No characteristics were associated with CH-SS.

\section{Clinical Outcome Variables}

Dichotomous clinical outcome variables were not different for participants with baseline data only ( $n=394)$ versus those with both baseline and week 24 data $(n=257)$; hence, only percentages of the outcome variables at baseline are presented in Figure 2. Of the 34 individuals who discontinued medication early, $24(71 \%)$ also discontinued the study. Fiftytwo percent of patients $(n=204)$ had virological response at treatment week 24 , and $40 \%$ $(n=158)$ achieved SVR. In the four days preceding each clinic visit, 27\% $(n=104)$ of patients were nonadherent with taking ribavirin, and in the four weeks preceding each clinic visit, only $8 \%(\mathrm{n}=31)$ were nonadherent to administering their weekly interferon injection. While $23 \%$ of patients $(\mathrm{n}=92)$ developed neuropsychiatric adverse events, only $3 \%(\mathrm{n}=11)$ and $9 \%$ $(n=34)$ required dose reductions or premature medication discontinuation, respectively, due to neuropsychiatric adverse events.

The means of symptom VAS scores at each time point are plotted in Figure 3. All symptoms significantly increased over the course of therapy from baseline to treatment week 24 (all p's $>0.0001$ ).

\section{Associations Between Social Support and Clinical Outcomes}

BL-SS and CH-SS were not associated with SVR, the primary endpoint of antiviral treatment (Table 2). The relationship between baseline SS and SVR was also nonsignificant in a generalized estimating equation (GEE) model where we categorized baseline SS into quartiles in order to look for nonlinear trends (data not shown). With regard to intermediate endpoints, the relationship between CH-SS and PEG adherence ( $\mathrm{RR}=0.98 ; 99 \%$ CI: 0.95 , 1.001) approached statistical significance $(\mathrm{p}=0.012)$, but was in a counterintuitive direction, such that as SS increased over time, PEG adherence decreased. BL-SS and CH-SS were not associated with virological response, ribavirin adherence, neuropsychiatric adverse events, or subsequent dose reductions or premature discontinuation of treatment due to such adverse events. 
The relationships between BL-SS and symptom-reporting via VASs are reported in Table 3. In unadjusted models, there was a main effect for the impact of BL-SS on overall symptoms, aches/pains, irritability, and fatigue (p's < 0.01 ). Despite low power availability to adequately test for interaction effects, there was a suggestive indication of an interaction between BL-SS and time, such that lower levels of BL-SS predicted worsening of overall symptoms, aches/pains, and irritability over the first 24 weeks of antiviral therapy (p's < 0.02). Since BL-SS and CES-D depression were correlated $(r=-0.46)$ at baseline, we assessed the impact of CES-D depression on these relationships in adjusted models. Although the inclusion of baseline CES-D mitigated the main effect of BL-SS in these models, the strength of the relationship (i.e., estimates) between BL-SS and symptoms over time was unaffected (p's < 0.02). Overall, CES-D depression was strongly associated with all symptoms in adjusted models (all p's $<0.001$ ). A 10-point increase in the CES-D depression score was associated with a $10 \%$ increase in symptoms.

\section{Post-Hoc Analyses of Four Functional Subscales and Social Integration Item}

In post-hoc analyses, we examined the association between the SS functional subscales (emotional/informational, tangible, affectionate, and positive social interaction) and the social integration item with all clinical outcomes to elucidate any relationships which may have been overlooked by using the overall SS scale in the primary analyses. None of the functional SS scales at baseline were associated with our primary endpoint, SVR. Change in emotional/informational SS was significantly associated with PEG adherence $(\mathrm{RR}=0.98$; 99\% CI: 0.95, 0.998; $\mathrm{p}<0.01$ ), such that adherence decreased as emotional/informational SS increased. Change in affectionate SS was significantly associated with dose reductions due to neuropsychiatric adverse events ( $R R=1.73 ; 99 \% \mathrm{CI}: 1.04,2.88 ; \mathrm{p}<0.01)$, such that the risk of dose reductions increased as affectionate SS increased. All other relationships with virological response, ribavirin adherence, neuropsychiatric adverse events, and premature treatment discontinuations, were not significant at $\alpha=0.01$ (data not shown). Taken together the number of post-hoc analyses conducted and the likelihood of Type 1 error contributing to the two relationships significant at $p=0.01$, we concluded that, similar to the results with the overall SS variable, no truly meaningful patterns emerged between any of the functional support subscales and these clinical outcomes. With regard to social integration, at baseline, patients $(n=390)$ reported a median of $5.5(\mathrm{IQR}=3-10)$ close relatives or friends with whom they felt at ease or could talk to. Social integration was not associated with SVR or any of the dichotomous clinical outcomes (data not shown).

The relationships between the four functional SS subscales and the five VAS symptoms were consistent with the primary analysis which employed the overall SS scale. In the majority of post-hoc analyses, the main effect of the baseline functional subscale was associated with the symptoms, and there was an increase in symptomatology over time. When models were adjusted for baseline depression, the relationship between the main effect of the functional subscale was mitigated, but the strength of the relationship between symptoms and baseline functional subscales over time was unchanged (data not shown).

\section{Discussion}

The relationship between SS and mental and physical health has been evaluated in several patient populations (32-34). Despite the physical, mental, social, and occupational challenges that accompany HCV treatment, and the presumption that adequate SS is important to treatment success, very few empirical investigations have examined the relationship between SS and treatment outcomes during antiviral therapy for chronic hepatitis $\mathrm{C}$. 
The VIRAHEP-C study provided a unique opportunity to investigate the relationship between SS and various clinical endpoints during treatment. In this study population, levels of SS were rather high, with a mean SS score (mean=79) higher than the mean score (mean=70) of the normative sample (27). Higher SS at baseline was associated with being employed, married (or in a relationship), being a nonsmoker, and not having public health insurance. Perhaps partially due to such high levels of support at baseline, we did not find any evidence that patients' SS impacts the hard endpoint of antiviral therapy: SVR.

With regard to intermediate clinical outcomes, baseline SS was inversely associated with symptom-reporting, such that lower baseline SS (both the overall score and functional subscale scores) was associated with higher symptoms of fatigue, aches/pains, irritability and overall symptomatology. This suggests that patients who perceive satisfying levels of SS tend to experience or report fewer symptoms during antiviral therapy. This is an important finding since research demonstrates that adverse side effects are the primary reason why treatment is discontinued prematurely $(35,36)$. We also discovered that baseline depression, which was moderately correlated with SS, was significantly associated with symptom-reporting. Baseline depression attenuated the main effect of SS on symptoms, but did not considerably impact the relationship between baseline SS and overall symptoms, aches/pains and irritability that occurred over the course of therapy. Thus, both SS and depression are important predictors of symptom-reporting. At baseline, depression may be of greater importance, but SS appears to continue to exert an effect on the perception of worse symptomatology over time. These findings suggest that SS is important to how a patient feels overall during treatment, and especially how they perceive aches/pains and irritability in particular. Sufficient SS may function to buffer patients from depression, which in turn, could positively affect treatment outcomes. This interpretation is consistent with both the current $\mathrm{HCV}$ literature as well as the broader psychosocial literature which suggests that social support improves health outcomes by buffering or protecting individuals from psychological distress $(32,37,38)$.

Baseline SS and change in SS, were not associated with ribavirin adherence, neuropsychiatric adverse events, or dose reductions and premature study discontinuation due to such adverse events. Although a borderline significant relationship was found between change in SS and PEG adherence, this relationship was counterintuitive to expectations, and we speculate, likely due to chance. Social integration (i.e., the quantity of one's support system) was unrelated to all outcomes of interest. Finally, our post-hoc analyses explored four functional subscales (emotional/informational, tangible, affectionate, and positive social interaction) and various clinical outcomes, which mirrored the primary analyses of overall SS. Specifically, the functional scales were not related to SVR or other categorical clinical outcomes, but they did predict levels of symptom-reporting.

In contrast to the results of this study, another study found that lower "social functioning" was associated with lower rates of SVR in a sample of 74 participants with recently acquired $\mathrm{HCV}$ infection, the majority of whom (85\%) were injection drug users. (39). A subscale of a questionnaire used to measure the effects of opiate treatment in injection drug users was used to measure social functioning(40). This scale measures three constructs, only one of which is social support: 1) social adjustment (i.e., proportion of time unemployed, number of houses lived in over the last 6 months); 2) drug culture involvement (i.e., proportion of acquaintances who are users); and social support measured as the number of close friends (quantity not quality of SS). Given that this measure taps a broad range of social functioning, it is not surprising that patients with worse social functioning (e.g., lack of stable housing) had lower rates of SVR in their study. In the current study, we employed a very specific measure of the quality of social support in a chronic HCV clinical trial population, and found that participants had relatively high levels of SS at baseline, which 
may partially explain why SS was not related to SVR in our study. The major methodological differences (e.g., patient populations, SS measurement) between the current study and Dore's study precludes any meaningful comparison, but rather highlights the potential role of moderating variables that may explain associations between SS and SVR.

A few limitations of this study preclude generalizabilty of these findings to dissimilar patient populations and clinical settings. This study occurred in the context of a large clinical study where participants, clinicians, and the academic medical centers in which the data were collected, may be strikingly different from other clinical settings in which HCV patients are treated. These patients had to screen and qualify for a rigorous NIH study which employed stringent exclusion criteria, including active substance abuse and unstable psychiatric disease. Thus, selection bias may have indirectly excluded patients with low SS by virtue of association with other patient characteristics (e.g., active drug use). In addition, these patients had relatively high levels of support (mean=79.2\%) compared to the general medical populations on which the MOS-SSS was normed (mean=70\%), and compared to the HCV population at large $(11,39,41-43)$. Therefore, these findings may not apply to dissimilar patient populations, especially those who may suffer from significant substance abuse or mental health comorbidities. Finally, the VIRAHEP-C research coordinators received extensive training in side effect management and adherence enhancement techniques(44), over and above that which is typical in most non-research clinical settings. As such, study staff could have provided the distinct type of functional support that is crucial to treatment success, thereby overshadowing, or rendering inconsequential, other forms of support provided by patients' family and friends. It is also possible that no statistical relationship was found between SS and treatment outcomes, like SVR, because the MOS-SSS instrument may have lacked the sensitivity or variability needed to capture differences in outcome variables.

The results of this study have implications for clinicians who treat HCV. First, our findings belie clinical experience and patients' opinions that SS is critical to treatment success (21, $45,46)$. However, this null relationship occurred in the context of patients having higher levels of support, and minimal substance abuse or psychiatric issues, findings which may not translate to patients with low levels of support or active addiction or psychiatric issues(39). Although SS was not directly associated with SVR, it did seem to buffer patients from experiencing multiple symptoms during treatment and perhaps help them cope better with side effects. It remains unclear as to whether an increase in symptomatology affects outcomes downstream, although studies indicate that adverse side effects are the primary cause of early treatment discontinuation $(7,15)$. Stabilizing SS and depressive symptoms prior to and during antiviral therapy may both be viable avenues to intervene to improve symptom management.

The results of this study also have implications for future research. These findings may not generalize to patients who receive treatment through standard (non-research) medical care. As such it is critical to determine if these findings can be replicated in other 'real world' clinical settings with patients who are often ineligible for participation in research protocols and may have lower levels of social support (e.g., individuals with psychiatric and addiction issues). It is likely that SS is diminished in patients who perceive higher rates of social stigma, and perhaps this leads to problems during standard treatment that are not observed during rigorously-controlled research protocols. Second, follow-up studies should investigate if an increase in symptomatology impacts treatment outcomes like SVR, as this was not the focus of the present investigation. Finally, as numerous studies suggest that depressive symptoms are related to negative events during antiviral treatment $(25,47,48)$, the development and testing of interventions to reduce depression is clearly a worthwhile empirically-supported research endeavor. 
In conclusion, in this study cohort we found no evidence that baseline or change in SS has a significant impact on SVR or other intermediate outcomes such as medication adherence, adverse events, or premature medication discontinuation. However, lower baseline SS was related to patients' experience of worse symptoms during treatment. Depression appeared to have an independent impact on symptom-reporting, over and above the impact of SS. The relationship between SS and treatment outcomes needs to be viewed with caution until future investigations can confirm or dispute these preliminary findings.

\section{Acknowledgments}

In addition to the authors of this paper, we would like to thank all the individuals who dedicated time and effort to the Virahep-C study: from the Beth Israel Deaconess Medical Center, Boston, MA: Nezam Afdhal, MD (Principal Investigator), Tiffany Geahigan, PA-C, MS (Research Coordinator); from the New York-Presbyterian Medical Center, New York, NY: Robert S. Brown, Jr., MD, MPH (Principal Investigator), Lorna Dove, MD, MPH (CoInvestigator), Shana Stovel, MPH (Study Coordinator), Maria Martin (Study Coordinator); from the University of California, San Francisco, San Francisco, CA: Norah Terrault, MD, MPH (Principal Investigator), Stephanie Straley, PA-C, Eliana Agudelo, PA-C, Melissa Hinds, BA (Clinical Research Coordinator), Jake Heberlein (Clinical Research Coordinator); from Rush University, Chicago, IL: Thelma E. Wiley, MD (Principal Investigator), Monique Williams, RN (Study Coordinator); from the University of Maryland, Baltimore, MD: Charles D. Howell, MD (Principal Investigator), Kelly Gibson (Project Coordinator), Karen Callison, RN (Study Coordinator), Jane Lewis, RN (Study Coordinator); from the University of Miami, Miami, FL: Lennox J. Jeffers, MD (Principal Investigator), Shvawn McPherson Baker, PharmD (Co-Investigator), Maria DeMedina, MSPH (Project Manager), Carol Hermitt, MD (Project Coordinator); from the University of Michigan, Ann Arbor, MI: Hari S. Conjeevaram, MD, MS (Principal Investigator), Robert J. Fontana, MD (Co-Investigator), Donna Harsh, MS (Study Coordinator); from the University of North Carolina, Chapel Hill, NC: Michael W. Fried, MD (Principal Investigator [K24 DK066144]), Scott R. Smith, PhD (Co-Investigator), Dickens Theodore, MD, MPH (CoInvestigator), Steven Zacks, MD, MPH, FRCPC (Co-Investigator), Roshan Shrestha, MD (Co-Investigator), Karen Dougherty, NP (Co-Investigator), Paris Davis (Study Coordinator), Shirley Brown (Study Coordinator); from St. Louis University, St. Louis, MO: John E. Tavis, PhD (Principal Investigator), Adrian Di Bisceglie, MD (CoInvestigator), Ermei Yao, $\mathrm{PhD}$ (Co-Investigator), Maureen Donlin, $\mathrm{PhD}$ (Co-Investigator), Nathan Cannon, BS (Graduate Student), Ping Wang, BS (Lab Technician); from Cedars-Sinai Medical Center, Los Angeles, CA: Huiying Yang, MD, PhD (Principal Investigator), George Tang, PhD (Project Scientist), Dai Wang, PhD (Project Scientist); from the University of Colorado Health Sciences Center, Denver, CO: Hugo R. Rosen, MD (Principal Investigator), James R. Burton, MD (Co-Investigator), Jared Klarquist (Lab Technician); from Veteran's Administration, Portland, OR: Scott Weston (Lab Technician); from Indiana University, Bloomington, IN: Milton W. Taylor, PhD (Principal Investigator), Corneliu Sanda, MD (post-doctoral associate), Takuma Tsukahara, MS (statistician), Mary Ferris (lab assistant); from the Data Coordinating Center, Graduate School of Public Health at the University of Pittsburgh, Pittsburgh, PA: Steven H. Belle, PhD (Principal Investigator), Geoffrey Block, MD (Co-Investigator), Jennifer Cline, BS (Data Manager), KyungAh Im, MS (Statistician), Stephanie Kelley, MS (Data Manager), Laurie Koozer, BA (Project Coordinator), Sharon Lawlor, MBA (Data Coordinator), Stephen B. Thomas, PhD (Co-Investigator), Abdus Wahed, PhD (Statistician), Yuling Wei, MS (Project Coordinator), Leland J. Yee, PhD (Consultant), Song Zhang, MS, MD (Statistician); from the National Institute of Diabetes and Digestive and Kidney Diseases: Patricia Robuck, PhD, MPH (Project Scientist), James Everhart, MD, MPH (Scientific Advisor), Jay H. Hoofnagle, MD (Scientific Advisor), Edward Doo, MD (Scientific Advisor), T. Jake Liang, MD (Scientific Advisor), Leonard B. Seeff, MD (Scientific Advisor); from the National Cancer Institute: David E. Kleiner, MD, PhD (Central Pathologist).

Financial Support for Virahep-C: The parent study was funded as a cooperative agreement by the National Institute of Diabetes and Digestive and Kidney Diseases (NIDDK) with co-support from the National Center on Minority Health and Health Disparities (NCMHD) and the Intramural Research Program of the National Cancer Institute (NCI) with further support under a Cooperative Research and Development Agreement (CRADA) with Roche Laboratories, Inc. Grant numbers: U01 DK60329, U01 DK60340, U01 DK60324, U01 DK60344, U01 DK60327, U01 DK60335, U01 DK60352, U01 DK60342, U01 DK60345, U01 DK60309, U01 DK60346, U01 DK60349, U01 DK60341. Other support: National Center for Research Resources (NCRR) General Clinical Research Centers Program grants: M01 RR00645 (New York Presbyterian), M02 RR000079 (University of California, San Francisco), M01 RR16500 (University of Maryland), M01 RR000042 (University of Michigan), M01 RR00046 (University of North Carolina) and K24 DK066144-01 (Fried).

Funding Support for the current project: This study was supported by Award Number KL2RR025746 (Evon) from the National Center for Research Resources, K23DK089004 (PI: Evon), the UNC Clinical and Translational Science Award (UL1RR025747; Esserman) and a mentoring grant (K24 DK066144-01;Fried). 


\section{Reference List}

1. Seeff LB, Hoofnagle JH. National Institutes of Health Consensus Development Conference: management of hepatitis C: 2002. Hepatology. 2002; 36 Suppl 1(5):S1-S2. [PubMed: 12407571]

2. Alter MJ, Kruszon-Moran D, Nainan OV, McQuillan GM, Gao F, Moyer LA, Kaslow RA, Margolis HS. The prevalence of hepatitis C virus infection in the United States, 1988 through 1994. N Engl J Med. 1999; 341(8):556-562. [PubMed: 10451460]

3. Di Bisceglie AM, Lyra AC, Schwartz M, Reddy RK, Martin P, Gores G, Lok AS, Hussain KB, Gish R, Van Thiel DH, Younossi Z, Tong M, Hassanein T, Balart L, Fleckenstein J, Flamm S, Blei A, Befeler AS. Hepatitis C-related hepatocellular carcinoma in the United States: influence of ethnic status. Am J Gastroenterol. 2003; 98(9):2060-2063. [PubMed: 14499788]

4. Kim WR. The burden of hepatitis C in the United States. Hepatology. 2002; 36 Suppl 1(5):S30-S34. [PubMed: 12407574]

5. Armstrong GL, Alter MJ, McQuillan GM, Margolis HS. The past incidence of hepatitis C virus infection: implications for the future burden of chronic liver disease in the United States. Hepatology. 2000; 31(3):777-782. [PubMed: 10706572]

6. Di Bisceglie AM, Hoofnagle JH. Optimal therapy of hepatitis C. Hepatology. 2002; 36 Suppl 1(5):S121-S127. [PubMed: 12407585]

7. Fried MW, Shiffman ML, Reddy KR, Smith C, Marinos G, Goncales FL Jr, Haussinger D, Diago M, Carosi G, Dhumeaux D, Craxi A, Lin A, Hoffman J, Yu J. Peginterferon alfa-2a plus ribavirin for chronic hepatitis C virus infection. N Engl J Med. 2002; 347(13):975-982. [PubMed: 12324553]

8. Spiegel BM, Younossi ZM, Hays RD, Revicki D, Robbins S, Kanwal F. Impact of hepatitis C on health related quality of life: a systematic review and quantitative assessment. Hepatology. 2005; 41(4):790-800. [PubMed: 15791608]

9. Zeuzem S, Feinman SV, Rasenack J, Heathcote EJ, Lai MY, Gane E, O'Grady J, Reichen J, Diago M, Lin A, Hoffman J, Brunda MJ. Peginterferon alfa-2a in patients with chronic hepatitis C. N Engl J Med. 2000; 343(23):1666-1672. [PubMed: 11106715]

10. Lindsay KL, Morishima C, Wright EC, Dienstag JL, Shiffman ML, Everson GT, Lok AS, Bonkovsky HL, Lee WM, Morgan TR, Ghany MG. Blunted cytopenias and weight loss: new correlates of virologic null response to re-treatment of chronic hepatitis C. Clin Gastroenterol Hepatol. 2008; 6(2):234-241. [PubMed: 18237873]

11. Janke EA, McGraw S, Garcia-Tsao G, Fraenkel L. Psychosocial issues in hepatitis C: a qualitative analysis. Psychosomatics. 2008; 49(6):494-501. [PubMed: 19122126]

12. Zickmund S, Ho EY, Masuda M, Ippolito L, LaBrecque DR. 'They Treated Me Like a Leper': Stigmatization and the Qualify of Life of Patients with Hepatitis C. Journal of General Internal Medicine. 2003; 18(10):835-844. [PubMed: 14521647]

13. McHutchison JG, Poynard T. Combination therapy with interferon plus ribavirin for the initial treatment of chronic hepatitis C. Semin Liver Dis. 1999; 19 Suppl 1:57-65. [PubMed: 10349693]

14. Kraus MR, Schafer A, Faller H, Csef H, Scheurlen M. Psychiatric symptoms in patients with chronic hepatitis C receiving interferon alfa-2b therapy. J Clin Psychiatry. 2003; 64(6):708-714. [PubMed: 12823087]

15. McHutchison JG, Gordon SC, Schiff ER, Shiffman ML, Lee WM, Rustgi VK, Goodman ZD, Ling $\mathrm{MH}$, Cort S, Albrecht JK. Interferon alfa-2b alone or in combination with ribavirin as initial treatment for chronic hepatitis C. Hepatitis Interventional Therapy Group. N Engl J Med. 1998; 339(21):1485-1492. [PubMed: 9819446]

16. Golden J, O'Dwyer AM, Conroy RM. Depression and anxiety in patients with hepatitis C: prevalence, detection rates and risk factors. Gen Hosp Psychiatry. 2005; 27(6):431-438. [PubMed: 16271658]

17. Loftis JM, Matthews AM, Hauser P. Psychiatric and substance use disorders in individuals with hepatitis C: epidemiology and management. Drugs. 2006; 66(2):155-174. [PubMed: 16451091]

18. Zickmund S, Ho EY, Masuda M, Ippolito L, LaBrecque DR. 'They Treated Me Like a Leper': Stigmatization and the Qualify of Life of Patients with Hepatitis C. Journal of General Internal Medicine. 2003; 18(10):835-844. [PubMed: 14521647] 
19. Cormier M. The role of hepatitis C support groups. Gastroenterol Nurs. 2005; 28 Suppl(3):S4-S9. [PubMed: 15976560]

20. Burgoyne RW. Exploring direction of causation between social support and clinical outcome for HIV-positive adults in the context of highly active antiretroviral therapy. AIDS Care. 2005; 17(1): 111-124. [PubMed: 15832838]

21. Rifai MA, Indest D, Loftis J, Hauser P. Psychiatric management of the hepatitis C patient. Curr Treat Options Gastroenterol. 2006; 9(6):508-519. [PubMed: 17081484]

22. Fraenkel L, McGraw S, Wongcharatrawee S, Garcia-Tsao G. Patients' experiences related to antiviral treatment for hepatitis C. Patient Education and Counseling. 2006; 62(1):148-155. [PubMed: 16098705]

23. Grebely J, Knight E, Genoway KA, Viljoen M, Khara M, Elliott D, Gallagher L, Storms M, Raffa JD, DeVlaming S, Duncan F, Conway B. Optimizing assessment and treatment for hepatitis C virus infection in illicit drug users: a novel model incorporating multidisciplinary care and peer support. Eur J Gastroenterol Hepatol. 2010; 22(3):270-277. [PubMed: 20425880]

24. Groessl EJ, Weingart KR, Kaplan RM, Clark JA, Gifford AL, Ho SB. Living with hepatitis C: qualitative interviews with hepatitis C-infected veterans. J Gen Intern Med. 2008; 23(12):19591965. [PubMed: 18807097]

25. Evon DM, Ramcharran D, Belle SH, Terrault NA, Fontana RJ, Fried MW. Virahep-C Study Group. Prospective Analysis of Depression During Peginterferon and Ribavirin Therapy of Chronic Hepatitis C: Results of the VIRAHEP-C Study. American Journal of Gastroenterology. 2009; 104:2949-2958. [PubMed: 19789525]

26. Conjeevaram HS, Fried MW, Jeffers LJ, Terrault NA, Wiley-Lucas TE, Afdhal N, Brown RS, Belle SH, Hoofnagle JH, Kleiner DE, Howell CD. Peginterferon and ribavirin treatment in African American and Caucasian American patients with hepatitis C genotype 1. Gastroenterology. 2006; 131(2):470-477. [PubMed: 16890601]

27. Sherbourne CD, Stewart AL. The MOS social support survey. Soc Sci Med. 1991; 32(6):705-714. [PubMed: 2035047]

28. Radloff LS. The CES-D Scale: A self-report depression scale for research in the general population. Applied Psychological Measurement. 1977; 1(3):385-401.

29. Chesney MA, Ickovics JR, Chambers DB, Gifford AL, Neidig J, Zwickl B, Wu AW. Self-reported adherence to antiretroviral medications among participants in HIV clinical trials: the AACTG adherence instruments. Patient Care Committee \& Adherence Working Group of the Outcomes Committee of the Adult AIDS Clinical Trials Group (AACTG). AIDS Care. 2000; 12(3):255-266. [PubMed: 10928201]

30. Cohen J. A power primer. Psychol Bull. 1992; 112(1):155-159. [PubMed: 19565683]

31. Zou G. A modified poisson regression approach to prospective studies with binary data. Am J Epidemiol. 2004; 159(7):702-706. [PubMed: 15033648]

32. Cohen, S. Social support and health. San Diego, CA US: Academic Press; 1985. Syme SLEd.

33. Ganster DC, Victor B. The impact of social support on mental and physical health. Br J Med Psychol. 1988; 61(Pt 1):17-36. [PubMed: 3282536]

34. Reblin M, Uchino BN. Social and emotional support and its implication for health. Curr Opin Psychiatry. 2008; 21(2):201-205. [PubMed: 18332671]

35. McHutchison JG, Bacon BR, Owens GS. Making it happen: managed care considerations in vanquishing hepatitis C. Am J Manag Care. 2007; 13 Suppl 12:S327-S336. [PubMed: 18095781]

36. Fried MW. Side effects of therapy of hepatitis C and their management. Hepatology. 2002; 36 Suppl 1(5):S237-S244. [PubMed: 12407599]

37. Cohen S, Wills TA. Stress, social support, and the buffering hypothesis. Psychol Bull. 1985; 98(2): 310-357. [PubMed: 3901065]

38. Bozo O, Toksabay NE, Kurum O. Activities of daily living, depression, and social support among elderly Turkish people. J Psychol. 2009; 143(2):193-205. [PubMed: 19306681]

39. Dore GJ, Hellard M, Matthews GV, Grebely J, Haber PS, Petoumenos K, Yeung B, Marks P, van BI, McCaughan G, White P, French R, Rawlinson W, Lloyd AR, Kaldor JM. Effective treatment of injecting drug users with recently acquired hepatitis $\mathrm{C}$ virus infection. Gastroenterology. 2010; 138(1):123-135. [PubMed: 19782085] 
40. Darke S, Hall W, Wodak A, Heather N, Ward J. Development and validation of a multidimensional instrument for assessing outcome of treatment among opiate users: the Opiate Treatment Index. Br J Addict. 1992; 87(5):733-742. [PubMed: 1591524]

41. Zacks S, Beavers K, Theodore D, Dougherty K, Batey B, Shumaker J, Galanko J, Shrestha R, Fried MW. Social stigmatization and hepatitis C virus infection. J Clin Gastroenterol. 2006; 40(3): 220-224. [PubMed: 16633123]

42. Willenbring ML. Integrating care for patients with infectious, psychiatric, and substance use disorders: concepts and approaches. AIDS. 2005; 19 Suppl 3:S227-S237. [PubMed: 16251823]

43. O'Brien AP, Cross WM, Higgs P, Munro I, Bloomer MJ, Chou KR. Australians living with and managing hepatitis C. Issues Ment Health Nurs. 2010; 31(8):520-524. [PubMed: 20624020]

44. Pherson-Baker S, Jones D, Duran RE, Klimas N, Schneiderman N. Development and implementation of a medication adherence training instrument for persons living with HIV: the MATI. Behav Modif. 2005; 29(2):286-317. [PubMed: 15657412]

45. Janke EA, McGraw S, Garcia-Tsao G, Fraenkel L. Psychosocial issues in hepatitis C: a qualitative analysis. Psychosomatics. 2008; 49(6):494-501. [PubMed: 19122126]

46. Fraenkel L, McGraw S, Wongcharatrawee S, Garcia-Tsao G. Patients' experiences related to antiviral treatment for hepatitis C. Patient Education and Counseling. 2006; 62(1):148-155. [PubMed: 16098705]

47. Martin-Santos R, ez-Quevedo C, Castellvi P, Navines R, Miquel M, Masnou H, Soler A, Ardevol M, Garcia F, Galeras JA, Planas R, Sola R. De novo depression and anxiety disorders and influence on adherence during peginterferon-alpha-2a and ribavirin treatment in patients with hepatitis C. Aliment Pharmacol Ther. 2008; 27(3):257-265. [PubMed: 17988237]

48. Lang JP, Melin P, Ouzan D, Rotily M, Fontanges T, Marcellin P, Chousterman M, Cacoub P. Pegylated interferon-alpha2b plus ribavirin therapy in patients with hepatitis $\mathrm{C}$ and psychiatric disorders: results of a cohort study. Antivir Ther. 2010; 15(4):599-606. [PubMed: 20587853] 


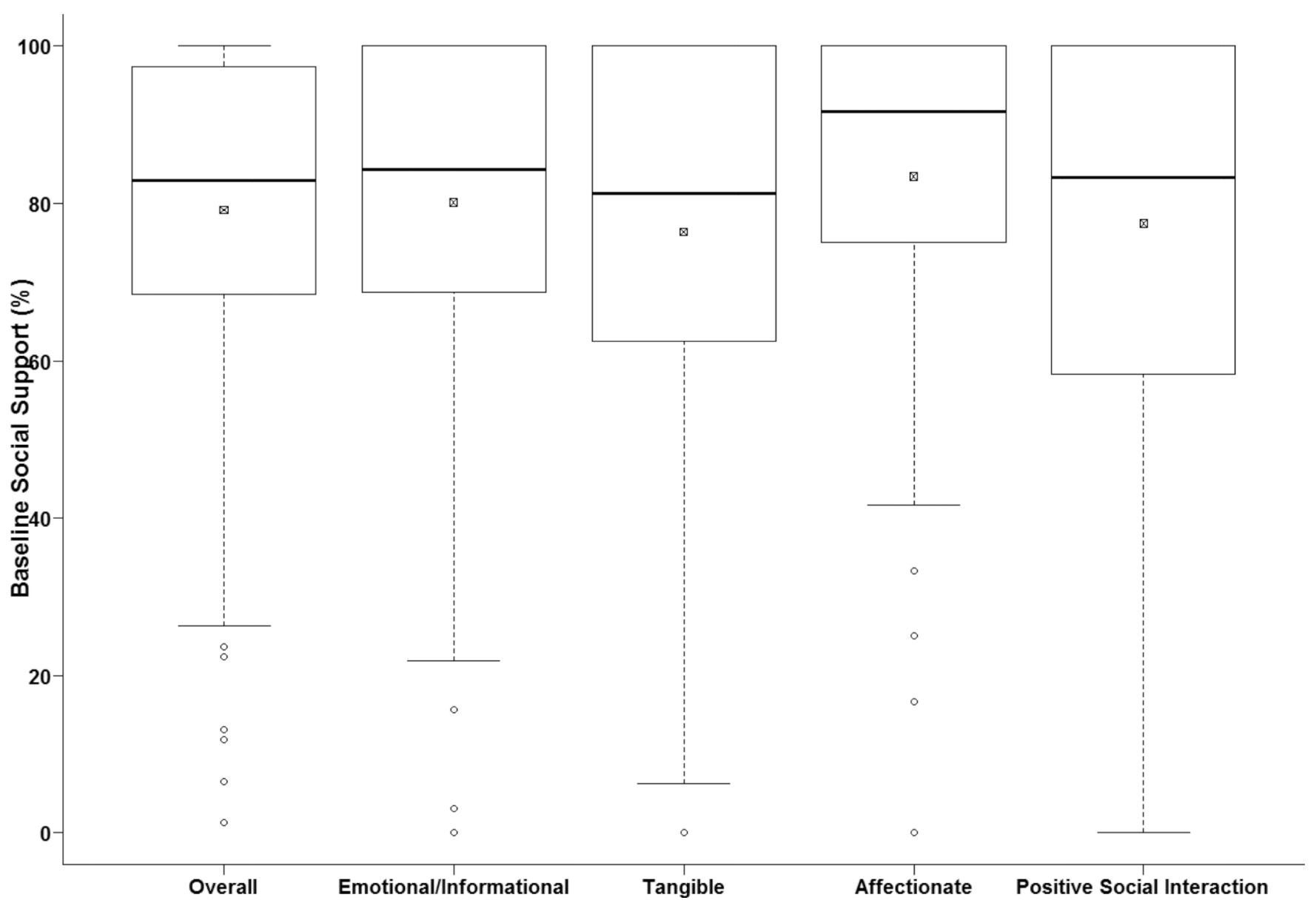

Fig. 1.

Box and whisker plot displaying the distribution of the baseline $(\mathrm{N}=394)$ overall social support scores and the four social support subscales. Median is represented by the dark line. The box is representative of the interquartile range (IQR), and the small box with the $x$ represents the mean. Data points outside of the whiskers are considered outliers. The median (IQR) for the fives scores were as follows: Overall: 82.9 (68.4-97.0); Emotional/ Informational: 84.4 (68.8-100); Tangible: 81.3 (62.5-100); Affectionate: 91.7 (75-100); Positive Social Interaction: 83.3 (58.3-100). The data are slightly negatively skewed. Most participants $(73 \%)$ reported baseline social support scores that were relatively high compared to normative samples 


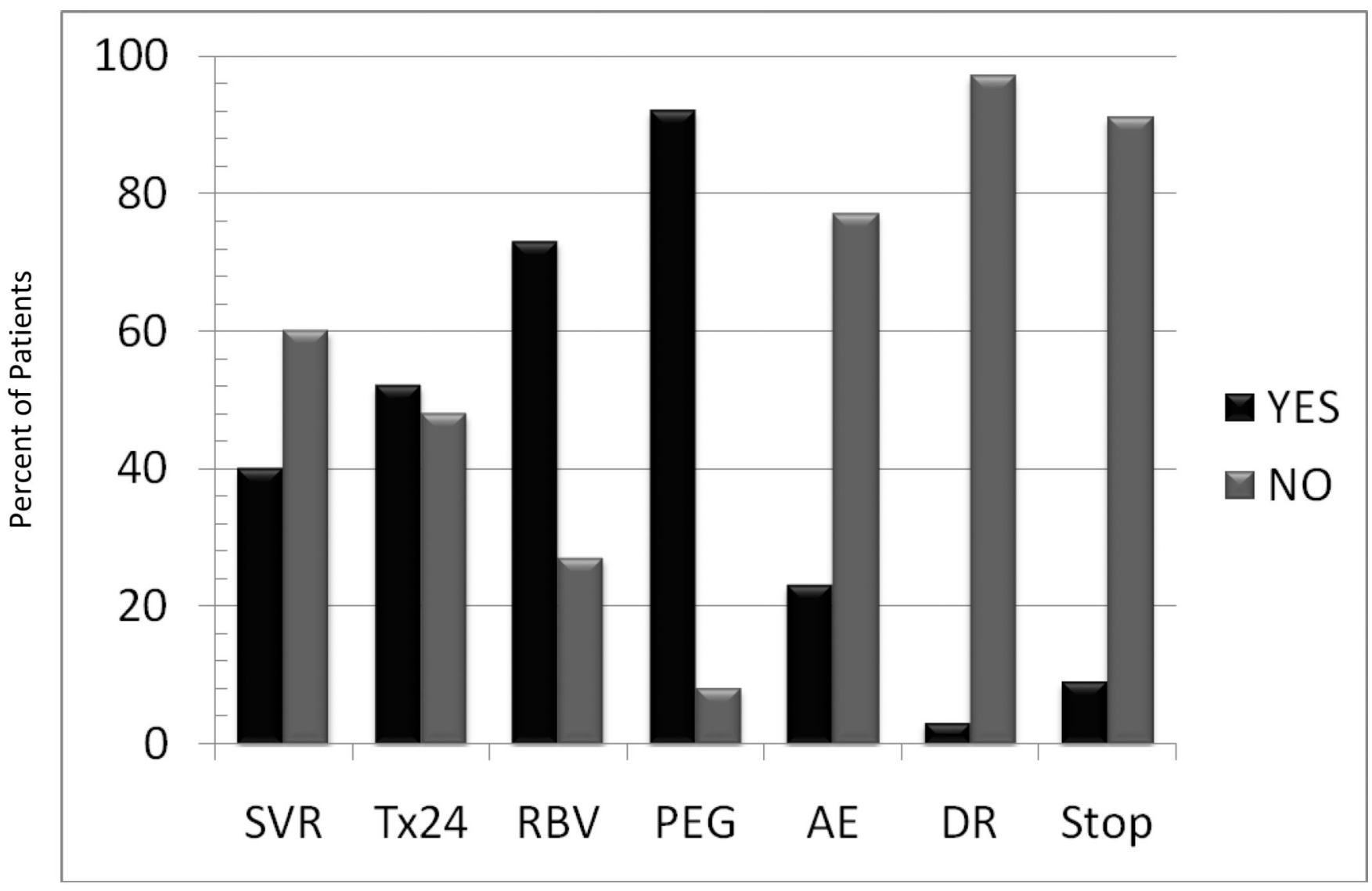

\section{Categorical Clinical Outcomes}

Fig. 2.

Percent categorical distributions of primary and intermediate clinical outcomes for entire sample $(\mathrm{N}=394)$. Baseline data is presented as there were no differences with individuals who were missing treatment week 24 data.

Note: SVR=Sustained Virologic Response; Tx24=Treatment Week 24 Virologic Response; RBV=Ribavirin Adherence; PEG=Peglyated Interferon Adherence; AE=Neuropsychiatric Adverse Events; DR=Dose Reductions Secondary to Neuropsychiatric Adverse Events; Stop=Discontinued Study Medications Early 


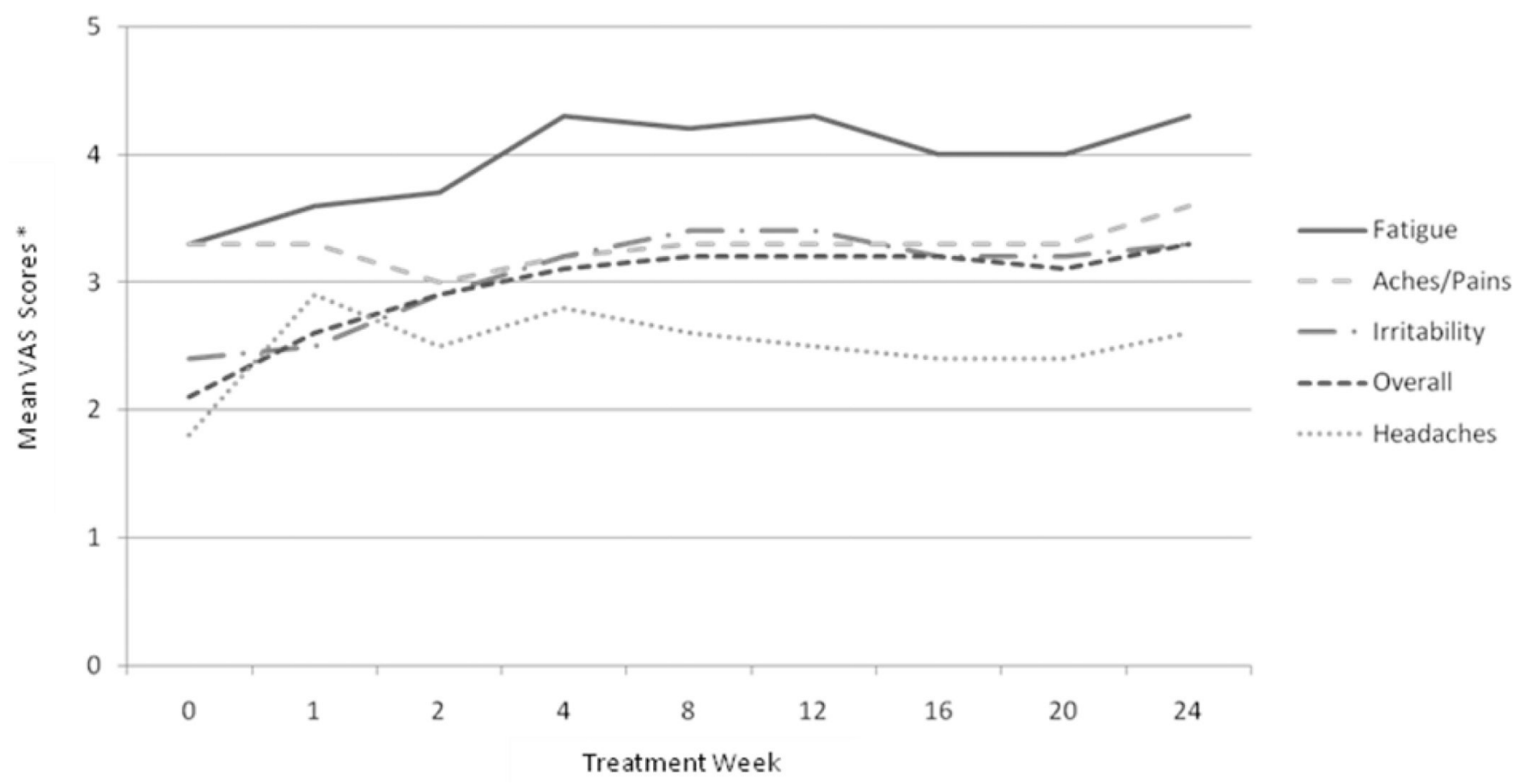

Fig. 3.

Means of self-reported symptoms during HCV treatment using Visual Analog Scales. All symptoms increased significantly over time from baseline through treatment week 24 (all p's <.0001). 


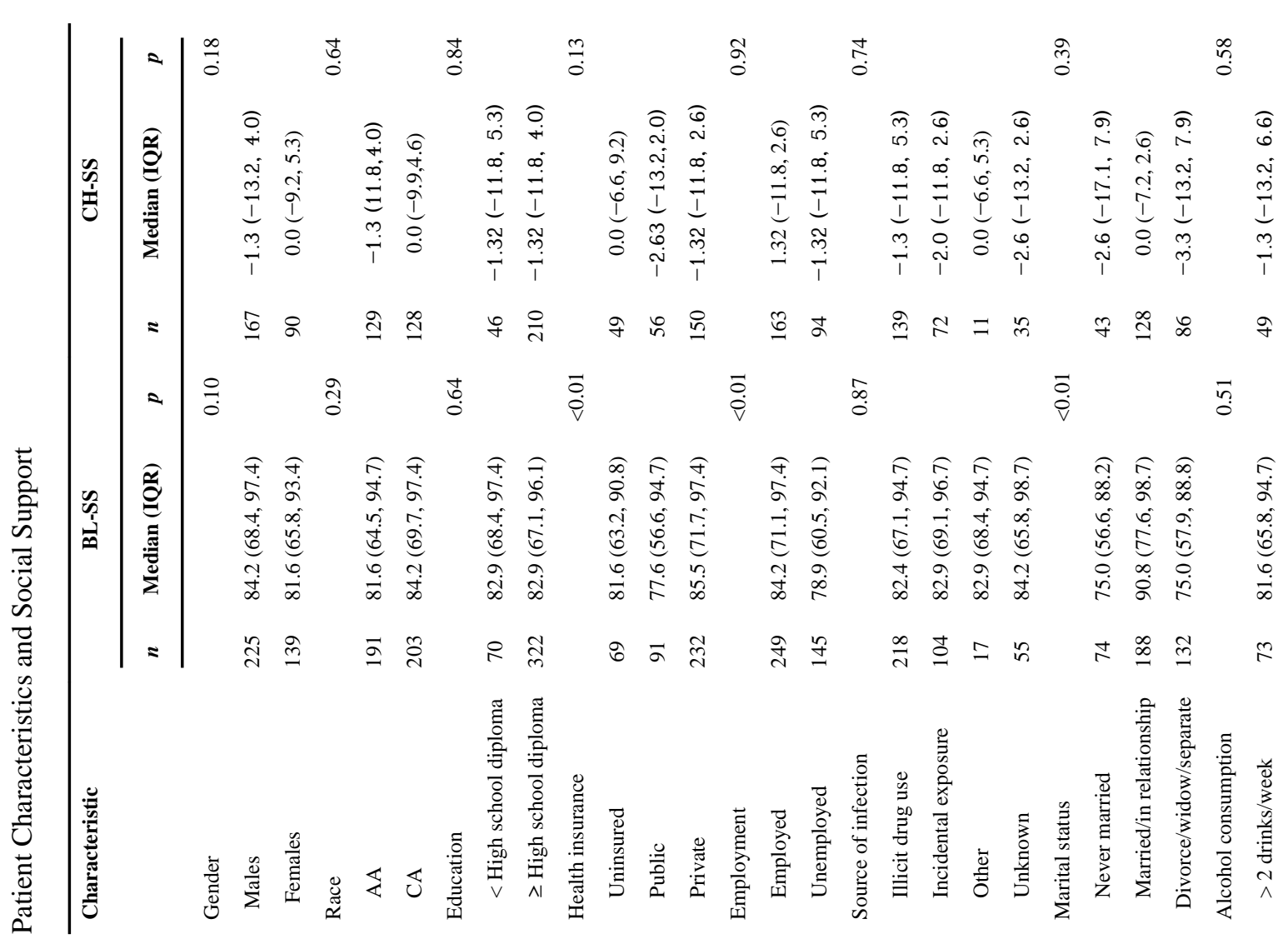




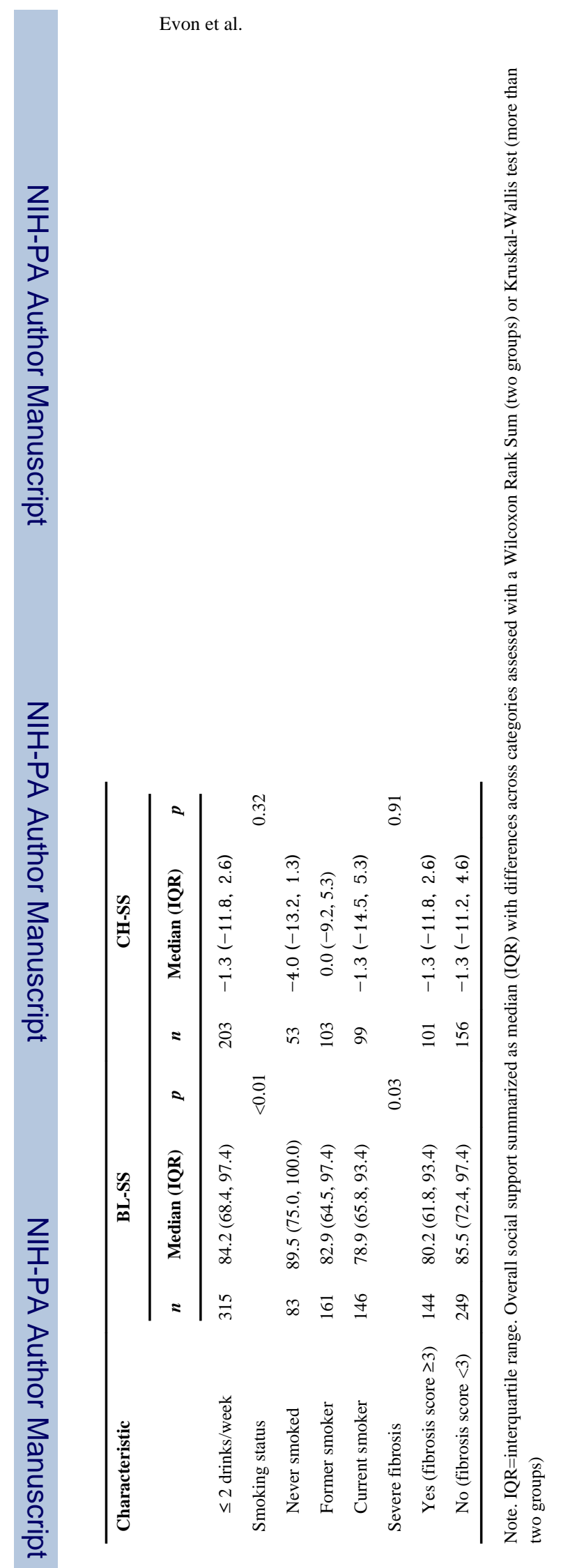

J Psychosom Res. Author manuscript; available in PMC 2012 November 1. 
